\title{
Una primera aproximación al nuevo Código Penal desde una vertiente laboral
}

AMPARO ESTEBAN GOMEZ

En el BOE número 281 de 24 de noviembre de 1995 se publicó, como de Penal (en adelante LO 10/95). Desde la promulgación de la Constitución se hacía necesaria una adaptación positiva del Código Penal a los nuevos valores proclamados en nuestra Carta Magna. Pues bien, constituye esta tarea de adaptación el principio informador básico que inspira el nuevo texto de C6́digo Penal.

Esta publicación no tiene como finalidad abarcar y pormenorizar todos y cada uno de los aspectos socio-laborales que, de seguro, se pueden extraer de la nueva redacción del Código Penal. Por el contrario, como indica su propio título, invita a una primera aproximación a la LO 10/95.

En este contexto y como modificaciones más significativas que contribuyen a esa adaptación al texto constitucional podemos señalar, siguiendo con ello la propia Exposición de Motivos de la LO 10/95, las siguientes:

En primer lugar, dos modificaciones, que podríamos denominar de carácter general y, que van a tener, lógicamente, una incidencia en materia socio-laboral, dada su generalidad.

Estos cambios son, de un lado, la reforma total del actual sistema de penas. Y, así, se adopta un sistema en el que se simplifica la regulación de las penas privativas de libertad ${ }^{2}$. Y, junto a ello, se introducen cambios en las penas pecuniarias, adoptando el sistema de días-multa ${ }^{3}$. Sistema, éste, según el cual, los Jueces o Tribunales determinarán, de forma siempre motivada, la extensión de la pena de multa dentro de los límites establecidos para cada delito. En cuanto a la duración de la pena de multa, el propio art. 50 de la LO 10/95 establece, con carácter general un máximo, en dos años ${ }^{4}$ y, un mínimo,

1 Profesora de Derecho del Trabajo. Universidad de Sevilla.

2 El nuevo texto de Código Penal dedica al tema todo el Título III, del libro I rotulado «De las penas".

${ }^{3}$ Cuya regulación se contempla en el art. 50 y sgs. de la LO 10/1995.

- A los efectos de cómputo, establece el art. 50.4 de la LO 10/95, cuando se fije la duración por meses o años, se entenderá que los meses son de 30 días y los años de trescientos sesenta. 
en cinco días. Se requiere, asimismo, que los Jueces o Tribunales fijen en la sentencia el importe de las cuotas, teniendo en cuenta para ello, de forma exclusiva, la situación económica del reo, deducida de su patrimonio, ingresos, obligaciones y cargas familiares y demás circunstancias personales del mismo. Ese importe de la cuota cuenta con unos límites: uno mínimo, de doscientas pesetas y, otro máximo, de cincuenta mil. Pues bien, aplicando este sistema a la pena de multa de seis a doce meses que se establece, de forma generalizada, para todos y cada uno de los delitos contemplados en el Título XV del Libro II de la LO 10/95, obtenemos una pena de multa que oscila entre un mínimo de 36.000 pesetas $^{5}$ y un máximo de 18.000 .000 de pesetas $^{6}$.

De otro lado y, dentro también de lo que hemos denominado cambios de carácter general, se contemplan a las detenciones, entradas y registros en el domicilio llevadas a cabo por autoridad o funcionario fuera de los casos permitidos por la ley, como formas agravadas de los correspondientes delitos comunes $^{7}$. De esta manera, se abandona el sistema, aún en vigor, que configura esas conductas como delitos especiales atenuados.

A continuación y, en segundo lugar, nos ocuparemos del que podríamos denominar el otro gran bloque de medidas adoptadas por el nuevo texto. Medidas éstas, que van a tener un mayor relieve en materia laboral, pudiendo destacarse, entre otras, las siguientes:

En primer lugar, podemos señalar la regulación de nuevas formas de delincuencia. Y así, entre otros y con carácter general, se contempla, de forma novedosa, el delito financiero, el tráfico de influencias; $y$, dentro de la materia que estamos considerando, se tipifica los delitos contra la Seguridad Social ${ }^{8}$.

Como segunda medida, en el nuevo texto de ha dado especial relieve a la tutela de los derechos fundamentales. Pues bien, esa tutela de los derechos fundamentales se ha traducido, en materia laboral, en la regulación sin precedentes de lo que podríamos calificar como la no discriminación en las relaciones laborales contenida en el art. 314 de la LO 10/95.

${ }^{5}$ Cuando adoptamos la extensión mínima, esto es, seis meses y, la cuota diaria mínima, o sea, doscientas pesetas. El cálculo es como sigue:

6 meses $\times 30$ días $=180$ dias;

180 días $\times 200$ pesetas $/$ día $=36.000$ pesetas.

${ }^{6}$ Cuando tomamos la extensión máxima, doce meses y, la cuota diaria, también máxima, establecida en cincuenta mil pesetas. El cálculo es, en este caso, el siguiente:

12 meses $\times 30$ días $=360$ dias;

360 días $\times 50.000$ pesetas $/$ día $=18.000 .000$ de pesetas.

${ }^{7}$ Regulación que se contiene en el Capitulo V, del Título XXI, del Libro II de la LO 10/95, titulado \&De los delitos cometidos por los funcionarios públicos contra las garantías constitucionales".

${ }^{8}$ Regulación prevista en el Título XIV, del Libro II de la LO 10/95, denominado «De los delitos contra la Hacienda Pública y contra la Seguridad Social». 
Por último, se ha procurado avanzar en el camino de la igualdad real y efectiva, tratando de cumplir la tarea que, en ese sentido, impone la Constitución a los poderes públicos. Se advierte que no es el Código Penal el instrumento más importante en esa tarea; pero junto a ello, también se destaca que puede contribuir a ella en una doble vertiente. De un lado, eliminando regulaciones que son un obstáculo para su realización; y, de otro lado, introduciendo medidas de tutela frente a situaciones discriminatorias. Quizás sea esta última idea, esto es, la creación de normas que otorgan una protección específica frente a las actividades tendentes a la discriminación, la que justifique el por qué de la inclusión, en el nuevo texto de Código Penal, del art. 314 que contempla la existencia de una grave discriminación contra alguna persona en el empleo, público o privado.

Una véz apuntado el por qué de la necesidad del nuevo texto y, seguidamente, qué cambios sustanciales aporta, destacamos, a continuación, en un análisis comparativo entre ambos textos, el aún en vigor ${ }^{9}$ y el contenido en la LO 10/95, aquellos aspectos más sobresalientes y que tengan un alcance directo en materia laboral. Sin ánimo de ser ésta una relación exhaustiva, podemos resaltar las siguientes novedades más destacables:

1.-El Decreto 3096/1973, de 14 de septiembre, por el que se publica el Código Penal, texto refundido conforme a la Ley 44/1971, de 15 de noviembre (BOE núms. 297 a 300, de 12 a 15 de diciembre de 1973 ) $^{10}$ (Decreto 3096/73 en adelante) ofrece una regulación dispersa de los delitos que podríamos denominar laborales. Por contra, siendo éste un aspecto a valorar como positivo del nuevo texto, la LO 10/95 dedica un título completo, concretamente el Título XV, del Libro II a lo que denomina “De los delitos contra los derechos de los trabajadores" ${ }^{11}$.

2.-A pesar de lo señalado en el párrafo anterior, la LO 10/95 contiene delitos que podríamos considerar impregnados, en algunas ocasiones, de lo laboral y que no se incluyen en ese Título XV del Libro II dedicado a los delitos contra los derechos de los trabajadores. Es el caso, entre otros, de los delitos contra la Seguridad Social regulados, junto a los delitos contra la Hacienda Pública, en el Título XIV del Libro II de la LO 10/95; el acoso sexual recogido en el art. 184 del nuevo texto, según el cual: «El que solicitare favo-

9 Texto refundido del Código Penal publicado por el Decreto 3096/1973, de 14 de septiembre, conforme a la Ley 44/1971, de 15 de noviembre.

${ }^{10}$ Aún en vigor en virtud de la Disposición Final séptima de la LO 10/95 según la cual: «El presente Código entrará en vigor a los seis meses de su completa publicación en el Boletín Oficial del Estado....

${ }^{11}$ Comprende los artículos 311 a 318. 
res de naturaleza sexual para sí o para un tercero prevaliéndose de una situación de superioridad laboral...." la revelación de secretos del art. 199 del mismo cuerpo legal, que prevé: «El que revelare secretos ajenos, de los que tenga conocimiento por razón de su oficio o sus relaciones laborales...n.

3.-Las penas establecidas para los delitos con incidencia laboral y que cuentan con antecedentes en el, aún vigente, texto del Decreto 3096/73 se elevan. Así, se toma, por regla general, como duración mínima (seis meses) lo que antes constituía la duración máxima ${ }^{12}$. Lo mismo se puede decir respecto a la pena de multa. Ya se señaló que puede llegar a la cuantía máxima de 18.000.000 de pesetas, cantidad, ésta, muy distinta y distante de las contempladas en el actual texto de Código Penal.

De otro lado, las penas previstas para los delitos recogidos en el Título XV del Libro II de la LO 10/95 se unifican en prisión de seis meses a tres años y multa de seis a doce meses. Esta regla cuenta, en el propio Título XV, con una sola excepción, la prevista en el art. 314 que contempla lo que hemos denominado la no discriminación en las relaciones laborales. Pues bien, para esta figura delictiva se prevé la pena de prisión de seis meses a dos años o multa de seis a doce meses.

4.-Desaparece el art. 427 del Decreto 3096/1073. Este artículo contempla las lesiones por infracción de las leyes de trabajo. Es éste un precepto que prácticamente viene siendo letra muerta, por su falta de aplicación por los Tribunales. Su desaparición del Código no llevaría a ningún vacío legal, pues los tipos previstos en el Código se limitan a las figuras de los arts. 420 y $421^{13}$, no a otros casos. Estas y otras razones han llevado a la desaparición de este artículo en el texto del nuevo Código Penal. Por tanto, una vez entrada en vigor la LO 10/95, serán de aplicación los preceptos encargados de tipificar las lesiones ${ }^{14}$.

5. El art. 348 bis a) del Decreto $3096 / 1973$ que regula los delitos contra la seguridad en el trabajo, sufre profundas e importantes modificaciones en el art. 316 del nuevo Código Penal. Entre otras, podemos señalar, en primer lugar, que el art. 348 bis habla de los que no "exijan", "faciliten" o "procuren». El art. 316 del nuevo texto sólo menciona los que no «faciliten». Entiendo que

12 El arresto mayor cuenta con una banda que oscila entre un mes y un dia, en su grado mínimo y, seis meses, en su grado máximo.

${ }^{13}$ Artículos comprendidos dentro del Capítulo IV, del Título VIII, del Libro II del Decreto 3096/73, titulado «De las lesiones".

${ }^{14}$ Arts. 147,a 156 de la LO 10/95. 
facilitar comprende procurar; pero no, en cambio, exigir con las consecuencias jurídicas que de ello se puedan derivar.

En segundo lugar, en el art. 348 bis a) se dice «...con infracción grave de las normas reglamentarias». El art. 316 de la LO 10/95 habla de "los que con infracción de las normas de prevención de riesgos laborales». No se exige, por tanto, según la nueva redacción, la gravedad de la infracción.

En tercer lugar, se contempla en el art. 348 bis a) el «...poniendo en peligro su vida o integridad física". Ahora, el art. 316 requiere, recogiendo en este punto el parecer mayoritario de la doctrina, que el peligro sea grave.

En cuarto lugar, el art. 348 bis a) prevé el peligro para "la vida o integridad física». Por tanto $\mathrm{y}$, atendiendo al tenor literal del precepto, queda excluido el supuesto de poner en peligro la salud del trabajador. Esta situación cambia, radicalmente, con la redacción del art. 316 del nuevo Código Penal que contempla, no sólo, el peligro grave en la vida y en la integridad física, al igual que antes, sino, también, el peligro grave en la salud. Es de esta manera cómo se amplía el alcance de las conductas punibles.

En quinto y, último lugar, en relación a las penas, existe una diferencia sustanciosa, agravándose considerablemente las mismas. Así, según el art. 348 bis a) la pena que corresponde es la de arresto mayor (en su grado mínimo, un mes y un día y, en su grado máximo, seis meses) o multa de 100.000 a 500.000 pesetas. En cambio, el art. 316 de la LO 10/95 establece las penas de prisión de seis meses a tres años $\mathrm{y}^{15}$ multa de seis a doce meses ${ }^{16}$.

6. -El art. 177 bis del vigente texto de Código Penal tipifica los delitos contra la libertad sindical y el derecho de huelga. Esta figura es recogida en el nuevo texto en el art. 315.1. Podemos poner de relieve una serie de diferencias significativas. En primer lugar, ambos preceptos contemplan a quienes «impidieren" o "limitaren" el ejercicio legítimo de la libertad sindical o del derecho de huelga. No obstante, en el art. 177 bis no se concretan las conductas materiales que puedan impedir o limitar esos derechos. Por contra, en la LO 10/95, en su art. 315.1, se abre la siguiente alternativa: ha de ser un limitar o impedir esos derechos, se entiende los de huelga o libertad sindical, mediante el engaño; o, en cambio, ha de ser un limitar o impedir mediante el abuso de situación de necesidad.

En segundo lugar, en el art. 177 bis se prevé «el ejercicio legítimo de líbertad sindical o del derecho de huelga». En el art. 315.1 sólo se menciona, a diferencia, "el ejercicio de la libertad sindical o el derecho de huelga". Quizás la supresión del término "legítimo" se deba a una corrección, por parte

15 Nótese la diferencia que con la nueva regulación las penas son acumulativas.

$16 \mathrm{~V}$. supra notas 4 y 5 . 
del legislador, de la redundancia, apuntada por la doctrina laboral, en la que incurría la redacción anterior al referirse al ejercicio legítimo.

En tercer lugar, se agravan las penas; $y$, así, en el art. 177 bis se penaliza el delito con arresto mayor y multa de 100.000 a 1.000 .000 de pesetas; ahora, el art. 315.1 contempla las penas de prision de seis meses a tres: años y multa de seis a doce meses ${ }^{17}$.

7.-El art. 499 bis, párrafo 1, núm. $1^{\circ}$ del Decreto 3096/73 prevé la impo-. sición de condiciones ilegales de trabajo. Teniendo en cuenta el art. $311.1^{\circ} \mathrm{del}$. nuevo texto podemos señalar una serie de novedades. En primer lugar, el art. 499 bis, en el párrafo que nos ocupa contempla las «maquinaciones o procedimientos maliciosos $n$; en cambio, el art. $311.1^{\circ}$ del nuevo Código habla de «engaño o abuso de situación de necesidad». No obstante ello, estimo que la diferencia de términos no tiene consecuencias jurídicas a destacar.

En segundo lugar, el art. 499 bis en el párrafo reseñado prevé las conductas que "perjudiquen" a los trabajadores en sus derechos. Por contra, el art. $311.1^{\circ}$ de la LO 10/95 circunscribe el supuesto a las situaciones que uperjudiquen, supriman o restrinjan" los citados derechos de los trabajadores. Con ello, por tanto, se amplía el abanico de los resultados que las conductas delictivas pueden ocasionar.

En tercer lugar, el art. 499 bis habla de derechos de los trabajadores «reconocidos por disposiciones legales o convenios colectivos sindicales». El art. $311.1^{\circ}$ va más allá y, extiende la protección a los derechos reconocidos a los trabajadores en el contrato individual.

En cuarto y, último lugar, en cuanto a las penas, éstas se agravan. $Y$, así, el art. 499 bis, párrafo 1 , núm. $1^{\circ}$ señala las penas de arresto mayor y multa de 100.000 a 2.000 .000 de pesetas. El nuevo texto, en su art. $311.1^{\circ}$ señala las penas de prisión de seis meses a tres años y multa de seis a doce meses ${ }^{18}$.

8.-Desaparece el art. 565 del Decreto 3096/1973, que contempla la imprudencia punible y se prevé en la LO 10/95 en su art. 12, que «las acciones $\mathrm{u}$ omisiones imprudentes sólo se castigarán cuando expresamente lo disponga la Ley".

Entendida cumplida la finalidad perseguida con este artículo y manifestada al comienzo del mismo, es obligado remitirse a la labor futura de los Tribunales y de la doctrina al perfilar y delimitar, con detalle, todos y cada uno de los aspectos que todo nuevo texto trae consigo.

17 V. supra notas 4 y 5 .

${ }^{18} \mathrm{~V}$. supra notas 4 y 5 . 